$\underline{\text { Review Articles }}$

\title{
Invasive Candidiasis in Non-Hematological Patients.
}

Malgorzata Mikulska, Matteo Bassetti, Sandra Ratto and Claudio Viscoli.

Division of Infectious Diseases, San Martino University Hospital, Genoa, Italy.

Correspondence to: Malorzata Mikulska, Division of Infectious Diseases, San Martino University Hospital, Genoa, Italy. m_mikulska@yahoo.com, claudio.viscoli@unige.it

Competing interests: The authors have declared that no competing interests exist.

Published: January 25, 2011

Received: January 4, 2011

Accepted: January 17, 2011

Mediterr J Hematol Infect Dis 2011, 3: e2011007, DOI 10.4084/MJHID.2011.007

This article is available from: http://www.mjhid.org/article/view/7453

This is an Open Access article distributed under the terms of the Creative Commons Attribution License (http://creativecommons.org/licenses/by/2.0), which permits unrestricted use, distribution, and reproduction in any medium, provided the original work is properly cited.

Abstract: Candida is one of the most frequent pathogens isolated in bloodstream infections, and is associated with significant morbidity and mortality. In addition to haematological patients, there are several other populations with a substantial risk of developing invasive candidiasis (IC). These include patients undergoing prolonged hospitalisation with the use of broad-spectrum antibiotics, those fitted with intravascular catheters, admitted to both adult and neonate intensive care units (ICU) or gastrointestinal surgery wards and subjects with solid tumours undergoing cytotoxic chemotherapy. As a general rule, every immunocompromised patient might be at risk of Candida infection, including, for example, diabetic patients.

The epidemiology of species responsible for IC has been changing, both at local and worldwide level, shifting from $C$. albicans to non-albicans species, that can be intrinsically resistant to fluconazole $(C$. krusei and, to some extent, $C$. glabrata), difficult to eradicate because of biofilm production $(C$. parapsilosis) or than might acquire resistance to azole during therapy.

Delaying the specific therapy has been shown to increase morbidity and mortality, but traditional microbiological diagnosis is poorly sensitive and slow. Thus, culture-based treatment may result in therapy started too late. In order to reduce the mortality in IC, several management strategies have been developed: prophylaxis, empirical and pre-emptive therapy. Compared to prophylaxis, the latter approaches allow to reduce the use of antifungals by targeting only patients at very high risk of IC. Non-invasive serological markers and scores based on clinical prediction rules such as the presence of risk factors or Candida colonisation, have been developed with the aim of allowing prompt initiation of treatment. Although the use of these diagnostic tools in pre-emptive strategies is promising, the performance and cost-effectiveness should be tested in large trials.

Agents recommended for initial treatment of candidemia in severely ill patients include echinocandins and lipid formulations of amphotericin $B$, while stable patients without risk factors for azole-resistance might be treated with fluconazole. 
Introduction: Candida is a yeast responsible for the majority of fungal infections in humans. This fungus causes pathologies of different severity, ranging from mucocutaneous infections to invasive disease that can involve any organ. The incidence of invasive candidiasis (IC), particularly candidemia, has increased significantly in recent years and Candida spp. is now the fourth most common pathogen isolated in blood cultures in the US. ${ }^{1}$ In Europe it ranks among the ten most frequently isolated pathogens. ${ }^{2,3}$ Candidemia is a life-threatening infection with high morbidity and mortality. ${ }^{4-7}$ Even in the most recent studies, crude mortality rates reached $50-60 \%$ in critically ill patients, ${ }^{8-10}$ although attributable mortality can be substantially lower.

Immunocompromised patients, such as those affected by solid tumours or haematological malignancies are at high risk for developing Candida infection. However, the widespread use of fluconazole prophylaxis in haematological and stem cell transplant settings might be responsible for a decreased incidence of invasive Candida infections in these populations. ${ }^{11}$ On the contrary, patients with multiple severe comorbidities, undergoing gastrointestinal surgery or admitted to ICU constitute now the largest population at risk for developing candidemia. ${ }^{12}$ In fact, IC can affect up to about $10 \%$ of all critically ill subjects. ${ }^{13,14}$ Fungal infections are being increasingly diagnosed in these patients, because advances in medical science now allow patients in desperate underlying conditions to survive. However, this is not obtained without a price, such as the development of infectious complications. Therefore, the population of subjects vulnerable to a range of infections is increasing and this trend will likely continue.

From a clinical point of view, Candida causes bloodstream infections, sometimes with endophtalmitis, followed by peritonitis and other abdominal infection and endocarditis. A matter of debate can be how often a blood culture positive for Candida represents the external sign of a deep-seated infection, or it is simply a bloodstream infection without localisation. Most of the patients included in studies on epidemiology or treatment of invasive candidiasis had candidemia (approximately 68-90\%), with or without localisation, while peritonitis was the second most common disease (approximately $7-30 \%$ of subjects). ${ }^{9,15,16}$ In a recent French study, isolated candidemia, IC with candidemia and IC without candidemia accounted each for $1 / 3$ of all episodes of IC. ${ }^{9}$ Additionally, Candida accounted for approximately $3 \%$ of all surgery-related peritoneal infections, both community-acquired and nosocomial. ${ }^{9}$

On the of main points regarding invasive Candida infection is the fact that delaying antifungal treatment significantly increases mortality. ${ }^{17-20}$ Even $12-24$ hours delay can result in twofold increase in crude mortality rate in candidemia. ${ }^{21,22}$ However, nosocomial fungal infections have one of the highest rates of inappropriate therapy, that consists mostly of omission of including an antifungal in the initial empirical therapy and use the of inadequate doses, all of which have been associated with increased mortality. ${ }^{12,21-23}$ Additionally, the estimated cost of each episode of IC in hospitalised adults is tremendous. ${ }^{24,25}$ Thus, high awareness of this infection, early diagnosis and appropriate prompt therapy remain the cornerstone of treatment.

During the last decade several new antifungal drugs have been developed and obtained approval for treatment of Candida infections. Therefore, treating a candidemia has become a difficult exercise, because of the need to make the appropriate choice at the appropriate time. In the following lines we will try to discuss epidemiology, risk factors, diagnosis and management of IC in non-haematological patients.

Epidemiology of invasive candidiasis: The epidemiology of Candida infections, both on a worldwide scale, and more importantly on the local level, has significant implications for the management of these infections.

During the past two decades, most hospitals have reported a progressive shift in the species of Candida. In the past, almost all the isolates responsible for bloodstream infections were C. albicans, whereas in recent years a growing proportion of episodes of candidemia have been caused by Candida species other than albicans. ${ }^{26-31}$ Although, C. albicans remains the predominant strain in most countries, ${ }^{9,32,33}$ non-albicans species are increasingly common and in some adult ICUs they were responsible for over $50 \%$ of candidemias. $^{29,34}$ The most common non-albicans species are $C$. parapsilosis and C. glabrata, followed by $C$. tropicalis and $C$. krusei ${ }^{9,29,35-37}$ Rare species reported to cause candidemia include $C$. lusitaniae, $C$. guilliermondii, and C. rugosa. ${ }^{12,35}$

Numerous studies have tried to find reasons for this shift and several risk factors have been associated with the emergence of non-albicans species. ${ }^{30,38,39}$ It is likely that the widespread use of fluconazole can predispose patients to the development of infections due to species that are intrinsically resistant to azoles or have developed resistance during treatment. Indeed, the previous use of fluconazole has been found to be a risk factor for the presence of non-albicans fungemia in many studies, ${ }^{29,30,40}$ even though others did not find the same association. ${ }^{28}$ In particular, risk factors for candidemia due to $C$. parapsilosis include the presence of in-dwelling devices, hyperalimentation and neonatal age. ${ }^{35}$ The specific risk factors associated with IC 
Table 1: Risk factors associated with invasive candidiasis in general and candidemia due to different Candida species.

\begin{tabular}{|c|c|}
\hline Candida species & Risk factor \\
\hline Candida in general & $\begin{array}{ll}\text { - } & \text { Prior abdominal surgery } \\
\text { - } & \text { Intravascular catheters } \\
\text { - } & \text { Parenteral nutrition } \\
\text { - } & \text { Use of broad-spectrum antibiotics } \\
\text { - } & \text { Immunosuppression, including corticosteroid therapy } \\
\text { - } & \text { Acute renal failure } \\
\text { - } & \text { Diabetes } \\
\text { - } & \text { Transplantation } \\
\text { - } & \text { Haemodialysis } \\
\text { - } & \text { Pancreatitis } \\
\end{array}$ \\
\hline C. tropicalis & - Neutropenia and bone marrow transplantation \\
\hline C. krusei & $\begin{array}{ll}\text { - } & \text { Fluconazole use } \\
\text { - } & \text { Neutropenia and bone marrow transplantation } \\
\end{array}$ \\
\hline C. glabrata & $\begin{array}{ll}- & \text { Fluconazole use } \\
\text { - } & \text { Surgery } \\
\text { - } & \text { Vascular catheters } \\
\text { - } & \text { Cancer } \\
\text { - } & \text { Older age } \\
\end{array}$ \\
\hline C. parapsilosis & $\begin{array}{ll}\text { - } & \text { Parenteral nutrition and hyperalimentation } \\
\text { - } & \text { Vascular catheters } \\
\text { - } & \text { Being neonate }{ }^{*} \\
\end{array}$ \\
\hline C. lusitaniae and C. guilliermondii & - $\quad$ Previous polyene use \\
\hline C. rugosa & - $\quad$ Burns \\
\hline
\end{tabular}

Adapted from the following references: ${ }^{6,31,35}$

Epidemics due to nosocomial horizontal transmission via hands of health personnel have been reported. ${ }^{45,46}$

and with different Candida species are outlined in table 1.

The overall rise in the incidence of non-albicans strains is alarming, since there are important differences among species. Specifically, the main difference between $C$. albicans and $C$. krusei or $C$. glabrata is the resistance to the most frequently used antifungal, i.e. fluconazole. ${ }^{41}$ Therefore, species identification and the knowledge of local epidemiology of Candida strains causing candidemia is of utmost importance for guiding appropriate empirical therapy. In vitro susceptibility testing of clinical isolates of Candida might prove valuable for guiding therapy in patients who have received prior antifungal treatment or who are not responding to first line therapy, especially if performed by experience microbiologists.

Risk factors for invasive candidiasis and predictive scores: The predominant source of invasive Candida infections is endogenous, from superficial mucosal and cutaneous colonisation to haematogenous dissemination, ${ }^{42}$ although cases of exogenous transmission due to contaminated materials or transmission from healthcare workers to patients and from patients to patients have been described. ${ }^{43-46}$ The suppression of the normal bacterial flora of the gastrointestinal tract by broad spectrum antibiotic therapy allows the yeast to proliferate and long-term and high density colonisation has been shown to predispose to candidemia. ${ }^{47,48}$ Numerous other conditions, frequent in hospitalised patients, such as steroid treatment and poor control of blood glucose concentrations (diabetes) have been described. In addition, parenteral nutrition, intravascular catheters or ischemia and reperfusion, may damage the integrity of the skin or gastrointestinal mucosa, with traslocation and bloodstream invasion. In particular, as much as one third of patients with recurrent gastrointestinal perforations, anastomotic leaks or necrotising pancreatitis develop IC (table 1). ${ }^{49,50}$

The effort to identify patients who are at high risk of developing IC has been made in order to reduce mortality by offering them prophylaxis, empirical or pre-emptive treatment. Once risk factors have been reported, they were combined to create reliable risk prediction scores.

Candida colonisation index (CI), reported in 1994, was studied in a surgical population with the aim of predicting patients who would develop IC, ${ }^{48}$ and was used as a base for pre-emptive therapy. ${ }^{51}$ Although it is highly predictive for IC, its routine use has been limited by workload required and consequent costs.

In 2006, Leon and colleagues described their Candida Score (CS) system, that was helpful to select 
patients who could benefit from early antifungal therapy (those with CS $>2.5$ were almost 8 times more likely to develop IC than those with $\mathrm{CS}<2.5){ }^{52}$ Subsequently, the same group validated their CS in a prospective multicenter trial that included 1107 patients admitted for at least 7 days to ICU. ${ }^{53} \mathrm{CS}$ was calculated as follows: 1 point for the presence of parenteral nutrition, surgery or multifocal Candida colonization, 2 points for severe sepsis. In patients with Candida Score $<3$, the incidence of IC was $2.3 \%$, thus allowing to withhold empirical antifungal treatment. On the contrary, one of four patients with a CS of 5 developed IC. ${ }^{53}$

Another clinical risk prediction score was developed by Ostrosky-Zeichner and colleagues. In this study, systemic antibiotic treatment or central venous catheter, combined with two or more of additional five parameters (parenteral nutrition, dialysis, major surgery, pancreatitis, treatment with steroids or other immunosuppressive agents), were able to identify patients with candidemia, with positive and negative predictive values of $10 \%$ and $97 \%$, respectively. ${ }^{54}$

Finally, Dupont and colleagues studied a predictive score for peritoneal Candida infection in an ICU population and found that the presence of 3 out of 4 factors (female gender, upper gastrointestinal tract origin of peritonitis, intraoperative cardiovascular failure and previous antibiotic therapy) had positive and negative predictive values of $67 \%$ and $72 \%$, respectively. ${ }^{55}$

Diagnosis of candidemia: Blood cultures remain the mainstay for the diagnosis of candidemia, although sensitivity is not optimal and the time from the blood sample collection to the microbiological response of a growing yeast is long. Furthermore, at least 24-48 hours are required for species identification and susceptibility testing. Traditional cultures from sterile sites other than the bloodstream (e.g. peritoneum), remain useful for the diagnosis IC, but more sensitive and more rapid diagnostic methods are needed.

In recent years, non-invasive markers have been investigated, which include serological markers (mannan, antimannan and (1,3)-beta-D-glucan) and polymerase chain reaction. Although the mannan and antimannan commercially available ELISA tests have been marketed for almost 10 years, the only data derive from a single-centre studies that differ significantly in terms of sensitivity and specificity. ${ }^{56-59}$ The $(1,3)$-betaD-glucan test has been marketed more recently in Europe and in the US. Despite promising results in various cohorts, no large prospective study able to evaluate sensitivity, specificity, and especially costeffectiveness, has been performed. ${ }^{60,61}$ The main problems of the routine use of (1,3)-beta-D-glucan are its high cost and high rate of false positive results. Indeed, (1,3)-beta-D-glucan is ubiquitous in nature contamination can be caused by concomitant bacterial bloodstream infections, presence of surgical gauzes, use of glucan-containing membranes for haemofiltration and use of albumin or immunoglobulins. ${ }^{62}$ For example, in a study that focused on the validation of the Candida Score, $(1,3)$ beta-D-glucan testing was performed in a subgroup of 240 patients with Candida species colonisation or invasive fungal infection. ${ }^{53}$ For a cut-off of $75 \mathrm{pg} / \mathrm{ml}$, good sensitivity of $77.8 \%$ was reported, but the specificity was low (52.7\%). In particular, among patients with a positive result, only $12 \%$ developed documented invasive candidiasis. However, a positive $(1,3)$-beta-D-glucan result is one of microbiological criteria defining a probable invasive fungal infection according to 2008 definitions of invasive fungal disease published by the European Organization for Research and Treatment of Cancer and the Infectious Diseases Mycoses Study Group (EORTC/MSG). ${ }^{63}$

Finally, two new rapid methods are available for species identification and they include matrix-assisted laser desorption ionization time-of-flight mass spectrometry (MALDI-TOF MS) and fluorescence insitu hybridization (FISH).

Management of candidemia in non-haematological setting: Different management strategies cen be used for managing suspected or documented IC, including prophylaxis, empirical or pre-emptive therapy and treatment of a culture-proven infection. Based on the incidence of IC, prophylaxis may be judged appropriate in patients with high risk of IC (incidence $>10 \%$ ). In settings with lower incidence rate, patients might benefit from pre-emptive strategies based on predictive scores. Obviously, the knowledge of local epidemiology helps to define the most appropriate antifungal therapy, based on the most frequent species and susceptibility patterns of Candida isolated in a single centre.

Prophylaxis, defined as administration of an antifungal to a patient with no evidence of infection, has been evaluated in surgical and critically ill patients in several studies and metaanalyses. ${ }^{33,64-73}$ Fluconazole prophylaxis reduced by approximately $50 \%$ the incidence of IC, and seemed associated with improved outcome. $^{70-72}$ Naturally, antifungal prophylaxis is efficacious and cost-effective in populations with high prevalence of IC, when the number of patients that need to receive the prophylactic treatment in order to prevent one episode of IC (number needed to treat) is low. On the other hand, the disadvantages of fluconazole prophylaxis include overtreatment, 
possible toxicity and profound influence on local epidemiology with the emergence of azole-resistant isolates. ${ }^{74}$ Therefore, antifungal prophylaxis might be indicated only for patients or procedures in which the rate of IC is higher than $10 \%$, as compared to the normal rates of $1-2 \%{ }^{41,54,75}$ In such populations, the number needed to treat is less than 20 , as compared with over 100 in an average population of ICU patients with the incidence of IC of $2 \%$.

Empirical treatment is defined as the administration of antifungals in the presence of persistent or refractory fever in subjects who are at high risk of developing a fungal infection. This strategy has been developed almost 3 decades ago for neutropenic cancer patients, when it became evident that the lack of sensitivity of microbiological and clinical findings was likely resulting in delayed diagnosis and increased morbidity and mortality. ${ }^{76}$ Although the first studies on empirical therapy had numerous methodological flaws, this fever-driven strategy is being used in different clinical settings and various antifungals are recommended for empirical treatment of invasive candidiasis, both in neutropenic and non-neutropenic patients. ${ }^{41}$ However, in ICU or surgery patients, there are several causes of protracted fever and, probably for this reason, in a randomised multicenter study in critically ill patients, the empirical therapy with fluconazole was not more beneficial than placebo. ${ }^{77}$

With the availability of diagnostic tools such as radiological imaging, invasive diagnostic procedures, improved cultures techniques and serological markers, it became evident that a diagnosis-driven approach was possible and should be pursued. Pre-emptive treatment is characterised by starting antifungal therapy when one or more microbiological or clinical markers result positive. Microbiological markers include multiple colonisation, positivity of mannan, (1,3)-beta-D-glucan or molecular testing. ${ }^{60,62}$ However, there is a certain degree of confusion between prophylaxis, empirical and pre-emptive treatment in patients with high risk of IC, as defined by high Candida colonisation index. In fact, the IDSA guidelines recommend a pre-emptive approach (although they continue to call it empirical treatment) based on clinical assessment of risk factors, serologic markers, and/or culture data from nonsterile sites, rather than fever. ${ }^{41}$

Despite all the advances in diagnostic tools, it is to be remembered that repeated blood cultures, both from $\mathrm{CVC}$ and peripheral line, remain the cornerstone of diagnosis of candidemia, and that any positive blood culture for Candida must be taken seriously and needs appropriate treatment.

Broad spectrum antifungals are recommended for the first line treatment while species identification is pending, but when species is known, a de-escalation can be recommended. ${ }^{41}$ The initial choice of antifungals depends on patient's clinical condition and the risk of azole-resistant strain, due to previous azole exposure or local epidemiology. ${ }^{41}$ For patients in severe or moderately severe clinical conditions (e.g. hemodynamically unstable, or with suspected concomitant organ involvement), echinocandins are the first choice because of their cidal activity against Candida and excellent toxicity profile. ${ }^{41}$ Liposomal amphotericin B - another fungicidal agent indicated for first line treatment in critically ill patients, is more expensive and probably associated with a higher toxicity.

Other aspects of treating invasive candidiasis: Once the initial therapy for candidemia is started, several clinical issues remain open. First, the efficacy of the treatment should be assessed by the documentation of blood cultures returning sterile. Indeed, the date of the first negative blood culture is important, because the recommended length of treatment is 14 days after the last positive blood culture and resolution of symptoms attributable to candidemia.

Second, the antifungal chosen initially can be changed on the basis of species identification or susceptibility testing. Thus, for stable patients with $C$. albicans or other azole-susceptible strains, fluconazole probably remains the drug of choice. Fluconazole might be preferred over echinocandins for treating $C$ parapsilosis, as caspofungin MICs for C. parapsilosis are higher than those for other Candida species. ${ }^{41,78}$ However, in a recent analysis of data from five clinical trials, that included 71 cases of infection due to $C$. parapsilosis, the success rate was comparable with other non-albicans species. ${ }^{79}$

Third, patients who improve clinically and who cleared Candida from the bloodstream, might be suitable for step-down oral therapy to complete the course of 14 days. The available oral antifungals are fluconazole, itraconazole, voriconazole and posaconazole. Fluconazole is an obvious choice for susceptible species, while voriconazole can be indicated as step-down therapy for C. krusei or voriconazole-susceptible $C$. glabrata and in ocular or cerebral infections, because of excellent tissue concentration.

Additionally, ophthalmologic fundus examination is indicated in all patients to exclude endocular infection, while endocarditis should be excluded in case of persistently positive blood cultures, known valve pathology or any other sign or symptom suggestive of endocardial involvement. As described elsewhere, in both these complicated cases the duration of treatment should be much longer (more than 4 weeks and up to lifelong suppressive therapy). ${ }^{41}$ 
Finally, intravenous catheter removal is strongly recommended for patients with candidemia. Indeed all guidelines, both on the management of candidiasis and on the management of catheter-related bloodstream infections, state clearly that catheters should be removed, even though one should admit that all statements indicate grade II or III of scientific validity of recommendation, in absence of data from properly randomised, controlled trials. ${ }^{41,80,81}$ However, the issue might still be controvertial since a recent study, based on a multivariate analysis of 842 adults included in candidemia trials, did not find any benefit of early central venous catheter removal (i.e. within 24 or 48 hours after initiation of antifungal therapy) on survival. $^{81}$

Conclusions: Candida is one of the most common causes of nosocomial bloodstream infection. Non-

\section{References:}

1. Wisplinghoff $\mathrm{H}$, Bischoff T, Tallent SM, Seifert H, Wenzel RP, Edmond MB: Nosocomial bloodstream infections in US hospitals: analysis of 24,179 cases from a prospective nationwide surveillance study. Clin Infect Dis 2004, 39:309-317. doi:10.1086/421946 PMid:15306996

2. Bouza E, Munoz P: Epidemiology of candidemia in intensive care units. Int J Antimicrob Agents 2008, 32 Suppl 2:S87-91. doi:10.1016/S0924-8579(08)70006-2

3. Bouza E, Perez-Molina J, Munoz P: Report of ESGNI01 and ESGNI02 studies. Bloodstream infections in Europe. Clin Microbiol Infect 1999, 5(Suppl 2):2S1-12.

4. Blumberg HM, Jarvis WR, Soucie JM, Edwards JE, Patterson JE, Pfaller MA, Rangel-Frausto MS, Rinaldi MG, Saiman L, Wiblin RT, Wenzel RP: Risk factors for candidal bloodstream infections in surgical intensive care unit patients: the NEMIS prospective multicenter study. The National Epidemiology of Mycosis Survey. Clin Infect Dis 2001, 33:177-186. doi:10.1086/321811 PMid:11418877

5. Jarvis WR: Epidemiology of nosocomial fungal infections, with emphasis on Candida species. Clin Infect Dis 1995, 20:15261530. PMid: 7548503

6. Wey SB, Mori M, Pfaller MA, Woolson RF, Wenzel RP: Risk factors for hospital-acquired candidemia. A matched case-control study. Arch Intern Med 1989, 149:2349-2353. doi:10.1001/archinte.149.10.2349 PMid:2802900

7. Richards MJ, Edwards JR, Culver DH, Gaynes RP: Nosocomial infections in combined medical-surgical intensive care units in the United States. Infect Control Hosp Epidemiol 2000, 21:510515. doi:10.1086/501795 PMid:10968716

8. Bougnoux ME, Kac G, Aegerter P, d'Enfert C, Fagon JY: Candidemia and candiduria in critically ill patients admitted to intensive care units in France: incidence, molecular diversity, management and outcome. Intensive Care Med 2008, 34:292299. doi:10.1007/s00134-007-0865-y PMid:17909746

9. Leroy O, Gangneux JP, Montravers P, Mira JP, Gouin F, Sollet JP, Carlet J, Reynes J, Rosenheim M, Regnier B, Lortholary O: Epidemiology, management, and risk factors for death of invasive Candida infections in critical care: a multicenter, prospective, observational study in France (2005-2006). Crit Care Med 2009, 37:1612-1618. doi:10.1097/CCM.0b013e31819efac0 PMid:19325476

10. Marriott DJ, Playford EG, Chen S, Slavin M, Nguyen Q, Ellis D, Sorrell TC: Determinants of mortality in non-neutropenic ICU patients with candidaemia. Crit Care 2009, 13:R115. neutropenic patients now constitute a large but heterogeneous population of patients at risk of IC, which includes subjects admitted to adult or neonatal ICU, undergoing abdominal surgery and those with cancer or numerous medical comorbidities 8e.g. diabetes). Morbidity and mortality associated with candidemia are significant and the epidemiology of species have been shifting towards non-albicans strains. Even though numerous risk factors for invasive Candida infection have been reported and several antifungals are widely available, the optimal management of candidemia remains a challenge. Prophylaxis might be beneficial in population with incidence $>10 \%$, while novel diagnostic techniques should be further studied to enable pre-emptive treatment in populations with lower incidence rates.

11. Kontoyiannis DP, Marr KA, Park BJ, Alexander BD, Anaissie EJ, Walsh TJ, Ito J, Andes DR, Baddley JW, Brown JM, et al: Prospective surveillance for invasive fungal infections in hematopoietic stem cell transplant recipients, 2001-2006: overview of the Transplant-Associated Infection Surveillance Network (TRANSNET) Database. Clin Infect Dis 2010 50:1091-1100. doi:10.1086/651263 PMid:20218877

12. Horn DL, Neofytos D, Anaissie EJ, Fishman JA, Steinbach WJ, Olyaei AJ, Marr KA, Pfaller MA, Chang CH, Webster KM: Epidemiology and outcomes of candidemia in 2019 patients: data from the prospective antifungal therapy alliance registry. Clin Infect Dis 2009, 48:1695-1703. doi:10.1086/599039 PMid:19441981

13. Eggimann P, Garbino J, Pittet D: Epidemiology of Candida species infections in critically ill non-immunosuppressed patients. Lancet Infect Dis 2003, 3:685-702. doi:10.1016/S1473. $\underline{\text { 3099(03)00801-6 }}$

14. Magnason $\mathrm{S}$, Kristinsson $\mathrm{KG}$, Stefansson $\mathrm{T}$, Erlendsdottir $\mathrm{H}$, Jonsdottir K, Kristjansson M, Jonmundsson E, Baldursdottir L, Sigvaldason H, Gudmundsson S: Risk factors and outcome in ICU-acquired infections. Acta Anaesthesiol Scand 2008, 52:1238-1245. doi:10.1111/j.1399-6576.2008.01763.x PMid:18823463

15. Kuse ER, Chetchotisakd P, da Cunha CA, Ruhnke M, Barrios C, Raghunadharao D, Sekhon JS, Freire A, Ramasubramanian V, Demeyer I, et al: Micafungin versus liposomal amphotericin B for candidaemia and invasive candidosis: a phase III randomised double-blind trial. Lancet 2007, 369:1519-1527. doi:10.1016/S0140-6736(07)60605-9

16. Pappas PG, Rotstein CM, Betts RF, Nucci M, Talwar D, De Waele JJ, Vazquez JA, Dupont BF, Horn DL, Ostrosky-Zeichner $\mathrm{L}$, et al: Micafungin versus caspofungin for treatment of candidemia and other forms of invasive candidiasis. Clin Infect Dis 2007, 45:883-893. doi:10.1086/520980 PMid: 17806055

17. Fraser VJ, Jones M, Dunkel J, Storfer S, Medoff G, Dunagan WC: Candidemia in a tertiary care hospital: epidemiology, risk factors, and predictors of mortality. Clin Infect Dis 1992, 15:414-421. PMid: 1520786

18. Nguyen MH, Peacock JE, Jr., Tanner DC, Morris AJ, Nguyen ML, Snydman DR, Wagener MM, Yu VL: Therapeutic approaches in patients with candidemia. Evaluation in a multicenter, prospective, observational study. Arch Intern Med 1995, 155:2429-2435. doi:10.1001/archinte.155.22.2429 PMid:7503601

19. Nucci M, Colombo AL, Silveira F, Richtmann R, Salomao R, Branchini ML, Spector N: Risk factors for death in patients with candidemia. Infect Control Hosp Epidemiol 1998, 19:846-850. doi:10.1086/647743 PMid:9831941 
20. Blot SI, Vandewoude KH, Hoste EA, Colardyn FA: Effects of nosocomial candidemia on outcomes of critically ill patients. Am J Med 2002, 113:480-485. doi:10.1016/S0002-9343(02)01248-2

21. Garey KW, Rege M, Pai MP, Mingo DE, Suda KJ, Turpin RS, Bearden DT: Time to initiation of fluconazole therapy impacts mortality in patients with candidemia: a multi-institutional study. Clin Infect Dis 2006, 43:25-31. 이:10.1086/504810 PMid:16758414

22. Morrell M, Fraser VJ, Kollef MH: Delaying the empiric treatment of candida bloodstream infection until positive blood culture results are obtained: a potential risk factor for hospital mortality. Antimicrob Agents Chemother 2005, 49:3640-3645. doi:10.1128/AAC.49.9.3640-3645.2005 PMid:16127033 PMCid:1195428

23. Parkins MD, Sabuda DM, Elsayed S, Laupland KB: Adequacy of empirical antifungal therapy and effect on outcome among patients with invasive Candida species infections. J Antimicrob Chemother 2007, 60:613-618. 이:10.1093/jac/dkm212 PMid:17576697

24. Cuenca-Estrella M, Rodriguez D, Almirante B, Morgan J, Planes AM, Almela M, Mensa J, Sanchez F, Ayats J, Gimenez M, et al: In vitro susceptibilities of bloodstream isolates of Candida species to six antifungal agents: results from a population-based active surveillance programme, Barcelona, Spain, 2002-2003. J Antimicrob Chemother 2005, 55:194-199. doi:10.1093/jac/dkh548 PMid:15618284

25. Fridkin SK: The changing face of fungal infections in health care settings. Clin Infect Dis 2005, 41:1455-1460. doi:10.1086/497138 PMid:16231257

26. Diekema DJ, Messer SA, Brueggemann AB, Coffman SL, Doern GV, Herwaldt LA, Pfaller MA: Epidemiology of candidemia: 3year results from the emerging infections and the epidemiology of Iowa organisms study. J Clin Microbiol 2002, 40:1298-1302. doi:10.1128/JCM.40.4.1298-1302.2002 PMid:11923348 PMCid: 140380

27. Passos XS, Costa CR, Araujo CR, Nascimento ES, e Souza LK, Fernandes Ode F, Sales WS, Silva Mdo R: Species distribution and antifungal susceptibility patterns of Candida spp. bloodstream isolates from a Brazilian tertiary care hospital. Mycopathologia 2007, 163:145-151. doi:10.1007/s11046-0070094-5 PMid:17334813

28. Shorr AF, Lazarus DR, Sherner JH, Jackson WL, Morrel M, Fraser VJ, Kollef MH: Do clinical features allow for accurate prediction of fungal pathogenesis in bloodstream infections? Potential implications of the increasing prevalence of nonalbicans candidemia. Crit Care Med 2007, 35:1077-1083. doi:10.1097/01.CCM.0000259379.97694.00 PMid:17312565

29. Bassetti M, Righi E, Costa A, Fasce R, Molinari MP, Rosso R, Pallavicini FB, Viscoli C: Epidemiological trends in nosocomial candidemia in intensive care. BMC Infect Dis 2006, 6:21. doi:10.1186/1471-2334-6-21 PMid:16472387 PMCid:1379648

30. Chow JK, Golan Y, Ruthazer R, Karchmer AW, Carmeli Y, Lichtenberg D, Chawla V, Young J, Hadley S: Factors associated with candidemia caused by non-albicans Candida species versus Candida albicans in the intensive care unit. Clin Infect Dis 2008, 46:1206-1213. doi:10.1086/529435 PMid: 18444857

31. Hachem R, Hanna H, Kontoyiannis D, Jiang Y, Raad I: The changing epidemiology of invasive candidiasis: Candida glabrata and Candida krusei as the leading causes of candidemia in hematologic malignancy. Cancer 2008, 112:2493-2499. doi:10.1002/cncr.23466 PMid:18412153

32. Tortorano AM, Peman J, Bernhardt H, Klingspor L, Kibbler CC, Faure O, Biraghi E, Canton E, Zimmermann K, Seaton S, Grillot R: Epidemiology of candidaemia in Europe: results of 28-month European Confederation of Medical Mycology (ECMM) hospital-based surveillance study. Eur J Clin Microbiol Infect Dis 2004, 23:317-322. doi:10.1007/s10096-004-1103-y PMid:6756909

33. Calandra T, Marchetti O: Clinical trials of antifungal prophylaxis among patients undergoing surgery. Clin Infect Dis 2004, 39 Suppl 4:S185-192. doi:10.1086/421955 PMid:15546116

34. Pereira GH, Muller PR, Szeszs MW, Levin AS, Melhem MS: Five-year evaluation of bloodstream yeast infections in a tertiary hospital: the predominance of non-C. albicans Candida species. Med Mycol 2010.
35. Krcmery V, Barnes AJ: Non-albicans Candida spp. causing fungaemia: pathogenicity and antifungal resistance. J Hosp Infect 2002， 50:243-260. doi:10.1053/jhin.2001.1151 PMid:12014897

36. Ruan SY, Lee LN, Jerng JS, Yu CJ, Hsueh PR: Candida glabrata fungaemia in intensive care units. Clin Microbiol Infect 2008 , 14:136-140 PMid:18042196

doi:10.1111/j.1469-0691.2007.01892.x

7. Trick WE, Fridkin SK, Edwards JR, Hajjeh RA, Gaynes RP: Secular trend of hospital-acquired candidemia among intensive care unit patients in the United States during 1989-1999. Clin Infect Dis 2002, 35:627-630. 이:10.1086/342300 PMid:12173140

38. Dimopoulos G, Ntziora F, Rachiotis G, Armaganidis A, Falagas ME: Candida albicans versus non-albicans intensive care unitacquired bloodstream infections: differences in risk factors and outcome. Anesth Analg 2008, 106:523-529, table of contents. doi:10.1213/ane.0b013e3181607262

39. Cohen Y, Karoubi P, Adrie C, Gauzit R, Marsepoil T, Zarka D, Clec'h C: Early prediction of Candida glabrata fungemia in nonneutropenic critically ill patients. Crit Care Med 2010, 38:826-830. PMid:20042858 doi:10.1097/CCM.0b013e3181cc4734

Viscoli C, Girmenia C, Marinus A, Collette L, Martino P Vandercam B, Doyen C, Lebeau B, Spence D, Krcmery V, et al: Candidemia in cancer patients: a prospective, multicenter surveillance study by the Invasive Fungal Infection Group (IFIG) of the European Organization for Research and Treatment of Cancer (EORTC). Clin Infect Dis 1999, 28:1071-1079. doi:10.1086/514731 PMid:10452637

41. Pappas PG, Kauffman CA, Andes D, Benjamin DK, Jr., Calandra TF, Edwards JE, Jr., Filler SG, Fisher JF, Kullberg BJ, Ostrosky-Zeichner L, et al: Clinical practice guidelines for the management of candidiasis: 2009 update by the Infectious Diseases Society of America. Clin Infect Dis 2009, 48:503-535. doi:10.1086/596757 PMid:19191635

42. Pfaller MA: Nosocomial candidiasis: emerging species, reservoirs, and modes of transmission. Clin Infect Dis 1996, 22 Suppl 2:S89-94.

43. Asmundsdottir LR, Erlendsdottir H, Haraldsson G, Guo H, Xu J, Gottfredsson M: Molecular epidemiology of candidemia: evidence of clusters of smoldering nosocomial infections. Clin Infect Dis 2008, 47:e17-24.

44. Bliss JM, Basavegowda KP, Watson WJ, Sheikh AU, Ryan RM: Vertical and horizontal transmission of Candida albicans in very low birth weight infants using DNA fingerprinting techniques. Pediatr Infect Dis J 2008, 27:231-235. doi:10.1097/INF.0b013e31815bb69d PMid:18277930

45. Hernandez-Castro R, Arroyo-Escalante S, Carrillo-Casas EM, Moncada-Barron D, Alvarez-Verona E, Hernandez-Delgado L, Torres-Narvaez P, Lavalle-Villalobos A: Outbreak of Candida parapsilosis in a neonatal intensive care unit: a health care workers source. Eur J Pediatr 2010, 169:783-787. doi:10.1007/s00431-009-1109-7 PMid:19957192

46. Vazquez JA, Sanchez V, Dmuchowski C, Dembry LM, Sobel JD, Zervos MJ: Nosocomial acquisition of Candida albicans: an epidemiologic study. J Infect Dis 1993, 168:195-201. PMid:8515108

47. Richet HM, Andremont A, Tancrede C, Pico JL, Jarvis WR: Risk factors for candidemia in patients with acute lymphocytic leukemia. Rev Infect Dis 1991, 13:211-215. PMid:2041951

48. Pittet D, Monod M, Suter PM, Frenk E, Auckenthaler R: Candida colonization and subsequent infections in critically ill surgical patients. Ann Surg 1994, 220:751-758. doi:10.1097/00000658-199412000-00008 PMid:7986142 PMCid:1234477

49. De Waele JJ, Vogelaers D, Blot S, Colardyn F: Fungal infections in patients with severe acute pancreatitis and the use of prophylactic therapy. Clin Infect Dis 2003, 37:208-213. doi:10.1086/375603 PMid:12856213

50. Calandra T, Bille J, Schneider R, Mosimann F, Francioli P Clinical significance of Candida isolated from peritoneum in surgical patients. Lancet 1989, 2:1437-1440. doi:10.1016/S01406736(89)92043-6 
51. Piarroux R, Grenouillet F, Balvay P, Tran V, Blasco G, Millon L, Boillot A: Assessment of preemptive treatment to prevent severe candidiasis in critically ill surgical patients. Crit Care Med 2004, 32:2443-2449. doi:10.1097/01.CCM.0000147726.62304.7F PMid:15599149

52. Leon C, Ruiz-Santana S, Saavedra P, Almirante B, Nolla-Salas J, Alvarez-Lerma F, Garnacho-Montero J, Leon MA: A bedside scoring system ("Candida score") for early antifungal treatment in nonneutropenic critically ill patients with Candida colonization. Crit Care Med 2006, 34:730-737. doi:10.1097/01.CCM.0000202208.37364.7D PMid:16505659

53. Leon C, Ruiz-Santana S, Saavedra P, Galvan B, Blanco A, Castro C, Balasini C, Utande-Vazquez A, Gonzalez de Molina FJ, Blasco-Navalproto MA, et al: Usefulness of the "Candida score" for discriminating between Candida colonization and invasive candidiasis in non-neutropenic critically ill patients: a prospective multicenter study. Crit Care Med 2009, 37:16241633. doi:10.1097/CCM.0b013e31819daa14 PMid:19325481

54. Ostrosky-Zeichner L, Sable C, Sobel J, Alexander BD, Donowitz G, Kan V, Kauffman CA, Kett D, Larsen RA, Morrison V, et al: Multicenter retrospective development and validation of a clinical prediction rule for nosocomial invasive candidiasis in the intensive care setting. Eur J Clin Microbiol Infect Dis 2007, 26:271-276. doi:10.1007/s10096-007-0270-z PMid:6756909

55. Dupont H, Bourichon A, Paugam-Burtz C, Mantz J, Desmonts JM: Can yeast isolation in peritoneal fluid be predicted in intensive care unit patients with peritonitis? Crit Care Med 2003, 31:752-757. doi:10.1097/01.CCM.0000053525.49267.77 PMid:12626979

56. Ellis M, Al-Ramadi B, Bernsen R, Kristensen J, Alizadeh H, Hedstrom U: Prospective evaluation of mannan and anti-mannan antibodies for diagnosis of invasive Candida infections in patients with neutropenic fever. J Med Microbiol 2009, 58:606615. doi:10.1099/jmm.0.006452-0 PMid:19369522

57. Prella M, Bille J, Pugnale M, Duvoisin B, Cavassini M, Calandra T, Marchetti O: Early diagnosis of invasive candidiasis with mannan antigenemia and antimannan antibodies. Diagn Microbiol Infect Dis 2005, 51:95-101. doi:10.1016/j.diagmicrobio.2004.08.015 PMid:15698714

58. Sendid B, Tabouret M, Poirot JL, Mathieu D, Fruit J, Poulain D: New enzyme immunoassays for sensitive detection of circulating Candida albicans mannan and antimannan antibodies: useful combined test for diagnosis of systemic candidiasis. J Clin Microbiol 1999, 37:1510-1517. PMid:10203514 PMCid:84817

59. Mikulska M, Calandra T, Sanguinetti M, Poulain D, Viscoli C, The 3rd European Conference on Infections in Leukemia Group: Mannan antigen and anti-mannan antibodies in the diagnosis of invasive candidiasis: recommendations from the European Conference on Infections in Leukemia. Crit Care 2010, 14.

60. Ostrosky-Zeichner L, Alexander BD, Kett DH, Vazquez J, Pappas PG, Saeki F, Ketchum PA, Wingard J, Schiff R, Tamura $\mathrm{H}$, et al: Multicenter clinical evaluation of the (1-->3) beta-Dglucan assay as an aid to diagnosis of fungal infections in humans. Clin Infect Dis 2005, 41:654-659. doi:10.1086/432470 PMid:16080087

61. Alam FF, Mustafa AS, Khan ZU: Comparative evaluation of (1, 3)-beta-D-glucan, mannan and anti-mannan antibodies, and Candida species-specific snPCR in patients with candidemia. BMC Infect Dis 2007, 7:103. doi:10.1186/1471-2334-7-103 PMid:17784947 PMCid:2075513

62. Presterl E, Parschalk B, Bauer E, Lassnigg A, Hajdu S, Graninger W: Invasive fungal infections and $(1,3)$-beta-D-glucan serum concentrations in long-term intensive care patients. Int $\mathrm{J}$ Infect Dis 2009, 13:707-712. doi:10.1016/j.ijid.2008.10.013 PMid:19157947

63. De Pauw B, Walsh TJ, Donnelly JP, Stevens DA, Edwards JE, Calandra T, Pappas PG, Maertens J, Lortholary O, Kauffman $\mathrm{CA}$, et al: Revised definitions of invasive fungal disease from the European Organization for Research and Treatment of Cancer/Invasive Fungal Infections Cooperative Group and the National Institute of Allergy and Infectious Diseases Mycoses Study Group (EORTC/MSG) Consensus Group. Clin Infect Dis 2008, 46:1813-1821. doi:10.1086/588660 PMid:18462102 PMCid:2671227
64. Jacobs S, Price Evans DA, Tariq M, Al Omar NF: Fluconazole improves survival in septic shock: a randomized double-blind prospective study. Crit Care Med 2003, 31:1938-1946. doi:10.1097/01.CCM.0000074724.71242.88 PMid:12847386

65. Sandven P, Qvist H, Skovlund E, Giercksky KE: Significance of Candida recovered from intraoperative specimens in patients with intra-abdominal perforations. Crit Care Med 2002, 30:541547. doi:10.1097/00003246-200203000-00008 PMid:11990912

66. He YM, Lv XS, Ai ZL, Liu ZS, Qian Q, Sun Q, Chen JW, Lei DX, Jiang CQ, Yuan YF: Prevention and therapy of fungal infection in severe acute pancreatitis: A prospective clinical study. World J Gastroenterol 2003, 9:2619-2621. PMid:14606111

67. Garbino J, Lew DP, Romand JA, Hugonnet S, Auckenthaler R, Pittet D: Prevention of severe Candida infections in nonneutropenic, high-risk, critically ill patients: a randomized, double-blind, placebo-controlled trial in patients treated by selective digestive decontamination. Intensive Care Med 2002, 28:1708-1717. doi:10.1007/s00134-002-1540-y PMid:12447512

68. Eggimann P, Francioli P, Bille J, Schneider R, Wu MM, Chapuis G, Chiolero R, Pannatier A, Schilling J, Geroulanos S, et al: Fluconazole prophylaxis prevents intra-abdominal candidiasis in high-risk surgical patients. Crit Care Med 1999, 27:1066-1072. doi:10.1097/00003246-199906000-00019 PMid:10397206

69. Lipsett PA: Clinical trials of antifungal prophylaxis among patients in surgical intensive care units: concepts and considerations. Clin Infect Dis 2004, 39 Suppl 4:S193-199. doi:10.1086/421956 PMid:15546117

70. Cruciani M, de Lalla F, Mengoli C: Prophylaxis of Candida infections in adult trauma and surgical intensive care patients: a systematic review and meta-analysis. Intensive Care Med 2005, 31:1479-1487. doi:10.1007/s00134-005-2794-y PMid:16172847

71. Shorr AF, Chung K, Jackson WL, Waterman PE, Kollef MH: Fluconazole prophylaxis in critically ill surgical patients: a metaanalysis. Crit Care Med 2005, 33:1928-1935; quiz 1936.

72. Playford EG, Webster AC, Sorrell TC, Craig JC: Antifungal agents for preventing fungal infections in non-neutropenic critically ill and surgical patients: systematic review and metaanalysis of randomized clinical trials. J Antimicrob Chemother 2006, 57:628-638. doi:10.1093/jac/dki491 PMid:16459344

73. Pelz RK, Hendrix CW, Swoboda SM, Diener-West M, Merz WG, Hammond J, Lipsett PA: Double-blind placebo-controlled trial of fluconazole to prevent candidal infections in critically ill surgical patients. Ann Surg 2001, 233:542-548. doi:10.1097/00000658-200104000-00010 PMid:11303137 PMCid:1421284

74. Bassetti M, Ansaldi F, Nicolini L, Malfatto E, Molinari MP, Mussap M, Rebesco B, Bobbio Pallavicini F, Icardi G, Viscoli $\mathrm{C}$ : Incidence of candidaemia and relationship with fluconazole use in an intensive care unit. J Antimicrob Chemother 2009, 64:625-629. doi:10.1093/jac/dkp251 PMid:19622536

75. Ostrosky-Zeichner L: Prophylaxis and treatment of invasive candidiasis in the intensive care setting. Eur J Clin Microbiol Infect Dis 2004, 23:739-744. doi:10.1007/s10096-004-1215-4 PMid:6756909

76. Pizzo PA, Robichaud KJ, Gill FA, Witebsky FG: Empiric antibiotic and antifungal therapy for cancer patients with prolonged fever and granulocytopenia. Am J Med 1982, 72:101111. doi:10.1016/0002-9343(82)90594-0

77. Schuster MG, Edwards JE, Jr., Sobel JD, Darouiche RO, Karchmer AW, Hadley S, Slotman G, Panzer H, Biswas P, Rex JH: Empirical fluconazole versus placebo for intensive care unit patients: a randomized trial. Ann Intern Med 2008, 149:83-90. PMid:18626047

78. Trofa D, Gacser A, Nosanchuk JD: Candida parapsilosis, an emerging fungal pathogen. Clin Microbiol Rev 2008, 21:606625. doi:10.1128/CMR.00013-08 PMid:18854483 PMCid:2570155

79. Colombo AL, Ngai AL, Bourque M, Bradshaw SK, Strohmaier KM, Taylor AF, Lupinacci RJ, Kartsonis NA: Caspofungin use in patients with invasive candidiasis caused by common nonalbicans Candida species: review of the caspofungin database. Antimicrob Agents Chemother 2010, 54:1864-1871. doi:10.1128/AAC.00911-09 PMid:20231388 PMCid:2863639 
80. Mermel LA, Allon M, Bouza E, Craven DE, Flynn P, O'Grady NP, Raad, II, Rijnders BJ, Sherertz RJ, Warren DK: Clinical practice guidelines for the diagnosis and management of intravascular catheter-related infection: 2009 Update by the Infectious Diseases Society of America. Clin Infect Dis 2009, 49:1-45. doi:10.1086/599376 PMid:19489710
81. Nucci M, Anaissie E, Betts RF, Dupont BF, Wu C, Buell DN, Kovanda L, Lortholary O: Early removal of central venous catheter in patients with candidemia does not improve outcome: analysis of 842 patients from 2 randomized clinical trials. Clin Infect Dis 2010, 51:295-303. doi:10.1086/653935 PMid:20578829 